\title{
ПСИХОАОГИЧЕСКИЕ ИССАЕДОВАНИЯ
}

\section{PSYCHOLOGICAL STUDIES}

\author{
DOI: 10.12731/2658-4034-2021-12-6-99-116 \\ УДК 316.6
}

\author{
КУЛЬТУРНО-ЭТНИЧЕСКИЙ ФАКТОР \\ ФОРМИРОВАНИЯ ЛИЧНОСТНОЙ БЕСПОМОЩНОСТИ: \\ ЭМПИРИЧЕСКОЕ ИССЛЕДОВАНИЕ НА МАТЕРИАЛЕ \\ МИГРАНТОВ ЦЕНТРАЛЬНОЙ АЗИИ
}

\section{Пономарева И.В., Пахомова Я.Н., Винькова Г.А.}

Введение. Неконтролируемые сочиальные, экономические и политические события, являющиеся травмирующими для субъекта, могут выступать предиктором формирования личностной беспомощности. В статье рассматриваются культурно-этнические факторы формирования личностной беспомощности и самостоятельности на материале исследования мигрантов из Центральной Азии. В качестве факторов выступают показатели этнической идентичности и культурных ценностей мигрантов.

Цель: выявить культурно-этнические факторы формирования личностной беспомощности на материале мигрантов Центральной Азии.

Методы и методология проведения работы. В соответствии с иелью исследования выборку составили мигранты Центральной Азии (N=222, средний возраст 20,84, медиана 20). Для изучения культурно-этнических особенностей личностной беспомощности и самостоятельности были сформированы две группь респондентов: испытуемые с личностной беспомощностью и испытуемые с самостоятельностью. В качестве методик исследования использовались: опросник личностной беспомощноости (М.О. Климова, Д.А. Ци- 
ринг), опросник «Типь этнической идентичности» (Г.У. Солдатова, С.В. Рыжсова), методика Г. Хофстеда «Модуль исследования иенностей», методика изучения культурных изенностей Ш. Шварияа.

Результаты. В ходе проведённого исследования было обнаружено, что особенности культурных иенностей и этнической идентичности выступают в роли фактора риска формирования личностной беспомощности. Показатели этноизоляционизма, этнофанатизма и мужественности, которые вносят вклад в дифференциацию респондентов - мигрантов стран Центральной Азии - на личностно беспомощных и самостоятельных. Выраженность перечисленных показателей способствует формированию самостоятельности. При низком уровне выраженности данные показатели выступают факторами формирования личностной беспомощуности.

Область применения результатов. Полученные данные составляют базу для разработки и апробации программ психопрофилактики и психологической коррекции личностной беспомощңности, программ сопровождения процесса адаптации у мигрантов.

Ключевые слова: личностная беспомощность; самостоятельность; культурно-этнический фактор; этническая идентичность; мигрантьл

\section{CULTURAL AND ETHNIC FACTOR OF PERSONAL HELPLESSNESS FORMATION: AN EMPIRICAL STUDY BASED ON THE MATERIAL OF CENTRAL ASIAN MIGRANTS}

\section{Ponomareva I.V., Pakhomova Ya.N., Vinkova G.A.}

Introduction. Uncontrolled social, economic and political events that are traumatic for the subject can act as a predictor of the formation of personal helplessness. The article examines the cultural and ethnic factors of the formation of personal helplessness and independence based on the study of migrants from Central Asia. The factors are indicators of ethnic identity and cultural values of migrants. 
Purpose: to identify cultural and ethnic factors of the formation of personal helplessness based on the material of migrants from Central Asia.

Methodology. In accordance with the purpose of the study, the sample consisted of migrants from Central Asia $(N=222$, average age 20.84, median 20). To study the cultural and ethnic characteristics of personal helplessness and independence, two groups of respondents were formed: subjects with personal helplessness and subjects with independence. The following research methods were used: the questionnaire of personal helplessness (M.O. Klimova, D.A. Tsiring), the questionnaire "Types of ethnic identity” (G.U. Soldatova, S.V. Ryzhova), the methodology of G. Hofstede's "Values Research Module”, a methodology for studying cultural values of Sh. Schwartz.

Results. In the course of the study, it was found that the features of cultural values and ethnic identity act as a risk factor for the formation of personal helplessness. Indicators of ethno-isolationism, ethno-fanaticism and masculinity, which contribute to the differentiation of respondentsmigrants from Central Asian countries - into personally helpless and independent. The severity of these indicators contributes to the formation of independence. With a low level of severity, these indicators act as factors in the formation of personal helplessness.

Practical implications. The data obtained form the basis for the development and testing of programs of psychoprophylaxis and psychological correction of personal helplessness, programs to support the adaptation process in migrants.

Keywords: personal helplessness; independence; cultural and ethnic factor; ethnic identity; migrants

\section{Введение}

Динамизм социальных процессов, происходящих в жизни современного общества, нестабильная общественно-экономическая ситуация последних десятилетий оказывают непредсказуемое и неподконтрольное для большинства людей воздействие, проводимые государством программы модернизации социальной и экономической сфер вызывают сложности не только финансового характера, 
но и психологического. Необходимость включённости во внедряемые инновационные процессы требуют помимо материальных, финансовых затрат, стрессоустойчивости людей, их психологической готовности к изменениям и нововведениям.

Неконтролируемые социальные, экономические и политические события, являющиеся травмирующими для субъекта, могут выступать предиктором формирования личностной беспомощности у последнего [9].

Личностная беспомощность, понимаемая как совокупность психологических и поведенческих особенностей индивида, влияет на поведение и деятельность последнего, накладывая отпечаток на его взаимоотношения с окружающими людьми, на его самоотношение. В рамках субъектно-деятельностного подхода, личностная беспомощность определяется как «качество субъекта, представляющее собой единство определённых личностных особенностей, возникающих в результате взаимодействия внутренних условий с внешними, определяющее низкий уровень субъектности, то есть низкую способность человека преобразовывать действительность, управлять событиями собственной жизни, ставить и достигать целей, преодолевая различного рода трудности» [9]. «Самостоятельность, как противоположная по своему наполнению характеристика субъекта, определяет особенности жизнедеятельности индивида таким образом, что его поведение, деятельность и взаимоотношения оказываются проявлением высокой способности преобразовывать действительность, выступать активным началом собственной жизненной позиции» [9].

Основным средовым фактором формирования у детей личностной беспомощности являются особенности взаимодействия в семье, а именно - нарушения в системе семейных взаимоотношений [6, $9,10]$. В исследовании Д.А. Циринг и И.В. Пономаревой эмпирически доказано, что личностная беспомощность преимущественно формируется при определённых типах дисгармоничных семейных взаимоотношений: жестокое обращение, противоречивый стиль воспитания, доминирующая гиперпротекция, повышенная моральная ответственность [6, 9]. 
Несмотря на достижения в разработке психологии личностной беспомощности, генезис исследований данного феномена свидетельствует о том, что во внимании учёных находятся лишь некоторые аспекты личностной беспомощности. Проблема формирования личностной беспомощности является актуальной, но недостаточно изученной. Основным фактором формирования личностной беспомощности выступают нарушения в стиле семейных взаимоотношений, помимо этого, в качестве причин возникновения личностной беспомощности могут быть неподконтрольные влиянию индивида травмирующие события, ряд социальных показателей: уровень материальной обеспеченности, полнота семьи, внешние серьёзные социальные, экономические, политические происшествия. Кроме того, мы предполагаем, что существуют культурно-этнические факторы формирования личностной беспомощности. Обнаруженная фрагментарность исследований личностной беспомощности препятствует целостному изучению субъекта, представлению психики в единстве её организации, изучению поведения, деятельности как опосредованных внутренним миром человека. Поэтому для более целостного и глубокого осмысления природы феномена личностной беспомощности необходим системный взгляд на средовые, а именно культурно-этнические факторы формирования данной характеристики. Исследование культурно-этнических детерминант личностной беспомощности позволит не только развить концепцию личностной беспомощности, обнаруживая новые данные о природе личностной беспомощности, но и создать теоретическую базу для решения прикладных задач, связанных с коррекцией изучаемого феномена, вопрос о которой также остаётся открытым на сегодняшний день.

Исходя из этого, целью данной работы: выявить культурно-этнические факторы формирования личностной беспомощности на материале мигрантов Центральной Азии. Не смотря на актуальность заявленной проблемы, исследований, посвящённых изучению роли культурно-этнических факторов в формировании личностной беспомощности, на данный момент не проводилось. 


\section{Материалы и методы исследования}

Целью данной работы является оценка влияния культурно-этнического фактора на формирование самостоятельности и личностной беспомощности на материале мигрантов Центральной Азии (Казахстан, Киргизия, Таджикистан, Туркменистан и Узбекистан). Общая схема эмпирического исследования определялась целью работы. В соответствии с целью исследования выборку составили мигранты Центральной Азии (222 человека, из них 108 респондентов мужского пола, 114 - женского; средний возраст - 20,84 лет, медиана - 20). 177 испытуемых на вопрос относительно рода занятий отметили, что являются студентами, 42 - работают, 3 человека - ведут домашнее хозяйство. Приезд в Россию связан с переездом на постоянное место жительство у 63 респондентов, с учебой на длительный срок у 156 респондентов, у 3 человек связан с сезонными работами. Опрос проходил с использованием Google Forms. Опросники были представлены на русском языке, которым все респонденты свободно владели. Для изучения культурно-этнических особенностей личностной беспомощности и самостоятельности были сформированы две группы респондентов: испытуемые с личностной беспомощностью и испытуемые с самостоятельностью.

В качестве методов исследования выступили анкетный опрос, метод тестирования, методы математической обработки данных. Тестирование и анкетный опрос проводились в индивидуальной форме. Анкета позволила собрать данные о социо-демографических показателях. В качестве методик исследования использовались: опросник личностной беспомощности (М.О. Климова, Д.А. Циринг) (Климова, Циринг, 2017), опросник «Типы этнической идентичности» (Г.У. Солдатова, С.В. Рыжова), методика Г. Хофстеда «Модуль исследования ценностей» (Hofstede, 2015), методика изучения культурных ценностей Ш.Шварца (Шварц, 2012). Математические методы статистической обработки данных представлены методами описательной статистики, дискриминантным анализом. Дискриминантный анализ используется для принятия решения о том, какие переменные различают (дискриминируют) две или бо- 
лее возникающие совокупности (группы). В данном исследовании дискриминантный анализ применяется с целью определения культурно-этнических детерминант личностной беспомощности и самостоятельности молодежи стран ближнего зарубежья.

\section{Результаты и их обсуждение}

С целью определения совокупности культурно-этнических факторов формирования личностной беспомощности нами был проведен дискриминантный анализ, результаты которого приведены в таблицах 1-4. В качестве метода был использован метод Уилкса, относящийся к пошаговым методам. В таблице 1 приведены коэффициент Х (Лямбда Уилкса), F-критерий и уровень значимости, характеризующие достоверные различия средних значений для изучаемых групп молодежи с личностной беспомощностью и самостоятельностью из Центральной Азии.

Таблицуа 1.

Средние значения, коэффициенты лямбда Уилкса, F-критерии и уровни значимости показателей культурно-этнического фактора у молодежи Центральной Азии с личностной беспомощностью и самостоятельностью

\begin{tabular}{|c|c|c|c|c|c|}
\hline \multirow{2}{*}{$\begin{array}{c}\text { Дискриминантные } \\
\text { переменные }\end{array}$} & \multicolumn{2}{|c|}{$\begin{array}{l}\text { Средние значения пока- } \\
\text { зателей культурно-этни- } \\
\text { ческого фактора у моло- } \\
\text { дежи Центральной Азии }\end{array}$} & \multirow[t]{2}{*}{$x$} & \multirow[t]{2}{*}{$\mathbf{F}$} & \multirow[t]{2}{*}{$\mathbf{P}$} \\
\hline & $\begin{array}{c}\text { с личностной } \\
\text { беспомощно- } \\
\text { стью } \\
\end{array}$ & \begin{tabular}{|c|} 
с само- \\
стоятель- \\
ностью \\
\end{tabular} & & & \\
\hline Конформность & 3,53036 & 4,18617 & 0,947 & 8,293 & 0,005 \\
\hline Традиции & 3,19464 & 4,07660 & 0,907 & 15,258 & 0,000 \\
\hline Доброта & 4,06607 & 5,19043 & 0,876 & 20,994 & 0,000 \\
\hline Универсализм & 3,79643 & 4,75213 & 0,902 & 16,147 & 0,000 \\
\hline Самостоятельность & 3,74286 & 5,07872 & 0,831 & 30,115 & 0,000 \\
\hline Стимуляция & 3,54643 & 4,46064 & 0,900 & 16,431 & 0,000 \\
\hline Гедонизм & 3,95179 & 4,76170 & 0,925 & 11,934 & 0,001 \\
\hline Власть & 2,83929 & 3,40638 & 0,954 & 7,088 & 0,009 \\
\hline Безопасность & 3,76071 & 4,87872 & 0,869 & 22,330 & 0,000 \\
\hline Достижения & 3,68214 & 4,84362 & 0,846 & 27,011 & 0,000 \\
\hline Дистанция власти (PDI) & 3,31250 & 3,12234 & 0,968 & 4,863 & 0,029 \\
\hline
\end{tabular}


Окончание табл. 1.

\begin{tabular}{|l|c|c|c|c|c|}
\hline Индивидуализм (IDV) & 2,82143 & 2,78191 & 0,998 &, 273 & 0,602 \\
\hline Мужественность (MAS) & 3,07589 & $\mathbf{3 , 2 7 6 6 0}$ & 0,960 & 6,236 & $\mathbf{0 , 0 1 4}$ \\
\hline $\begin{array}{l}\text { Избегание неопределенности } \\
\text { UAI) }\end{array}$ & $\mathbf{3 , 3 4 3 7 5}$ & 3,17553 & 0,979 & 3,140 & $\mathbf{0 , 0 7 8}$ \\
\hline Этнонигилизм & 13,62500 & $\mathbf{1 6 , 4 3 6 1 7}$ & 0,924 & 12,222 & $\mathbf{0 , 0 0 1}$ \\
\hline Этническая индифферентность & 8,66071 & 8,27660 & 0,997 & 0,482 & 0,489 \\
\hline $\begin{array}{l}\text { Позитивная этническая } \\
\text { идентичность }\end{array}$ & $\mathbf{6 , 1 6 0 7 1}$ & 4,11702 & 0,960 & 6,189 & $\mathbf{0 , 0 1 4}$ \\
\hline Этноэгоизм & 14,51786 & $\mathbf{1 6 , 5 3 1 9 1}$ & 0,966 & 5,216 & $\mathbf{0 , 0 2 4}$ \\
\hline Этноизоляционизм & 14,35714 & $\mathbf{1 6 , 5 9 5 7 4}$ & 0,956 & 6,800 & $\mathbf{0 , 0 1 0}$ \\
\hline Этнофанатизм & 14,19643 & $\mathbf{1 5 , 2 4 4 6 8}$ & 0,987 & 1,877 & $\mathbf{0 , 0 1 7}$ \\
\hline
\end{tabular}

Согласно результатам дискриминантного анализа, с фактом формирования личностной беспомощности / самостоятельности связаны показатели культурных ценностей, этнической идентичности и выученной беспомощности. Культурно-этнические характеристики, выступающие в качестве дискриминантных переменных, указанные в таблице 1, выступают в качестве переменных, различия по которым между группами молодежи-мигрантов с личностной беспомощностью и самостоятельностью статистически достоверны, кроме показателей этнической индифферентности и индивидуализма (IDV). Обращаясь к средним значениям, можно отметить, что сформированность культурных ценностей выступает фактором, предупреждающим развитие личностной беспомощности. Ценности и ценностные ориентации, выступая в качестве ориентира, формируют самостоятельность субъекта. Дистанция власти, согласно полученным результатам, в большей степени выражена у респондентов с личностной беспомощностью. «Дистанция власти - это степень, в которой люди, не имеющие власти или имеющие незначительную власть, согласны с тем, что власть в обществе распределяется неравномерно» (Hofstede, 2015). Показатели дистанции власти разные в зависимости от страны проживания и её культурных особенностей. Хофстед отмечает, что на уровне культуры происходит «коллективное программирование» сознания, включающее в качестве этапов опыт взаимоотношений в семье, школе, университете (или другом учеб- 
ном заведении) и на работе, а также особенности государственной власти и идеологии страны. В семьях из стран с большой дистанцией власти ребёнку транслируется необходимость уважительного и почтительного отношения к взрослым, а независимое поведение и самостоятельность не поощряются. Родители остаются на протяжении всей жизни авторитетом для своего ребёнка, который принимает все важные решения только при их одобрении. В семьях стран с маленькой дистанцией власти ребёнок воспринимается родителями как партнёр, отношения с раннего возраста строятся на равных правах, ребёнка учат принимать самостоятельные решения и нести за них ответственность. Так, согласно полученным результатам, большая дистанция власти выступает в качестве фактора, повышающего риск формирования личностной беспомощности.

Анализируя показатель мужественности (MAS), можем отметить, что он в большей степени характерен испытуемым с самостоятельностью. Согласно Хофстеду, принятые в обществе культурные стереотипы относительно мужественности и женственности начинают транслироваться ребёнку ещё в семье. Так, в странах с мужественной культурой детей учат честолюбию, соперничеству, амбициозности, умению заявлять о себе, формируют лидерские качества и стремление к успеху. В женственных культурах детям передают такие ценности, как скромность, послушание, уважение старших, приоритет гармоничных отношений с окружающими над личным успехом, формируют умение находить компромисс в спорных ситуациях, а также адаптироваться к обществу. Дети, воспитанные в культуре женственности, не стремятся к достижению высоких результатов. Мужественность, выступая культурной ценностью, препятствует формированию личностной беспомощности и характерна для молодёжи с самостоятельностью.

Следующий показатель национальной культуры - избегание неопределённости (UAI) - в большей степени свойственен респондентам с личностной беспомощностью. Высокий уровень избегания неопределённости подразумевает более чёткое следование правилам и нормам, определение границ возможного и доступного, опасного и 
неопасного, что способствует снижению тревоги, страха, неясности и непредсказуемости. В странах с высокой выраженностью избегания неопределённости люди испытывают потребность в формализованных чётких указаниях и нормах поведения, строгом разграничении на «плохое» и «хорошее». В культурах с низким уровнем избегания неопределённости люди характеризуются спокойствием, терпимостью и беззаботностью. Нормы взаимоотношений в данных странах также присутствуют, однако жители понимают, что в зависимости от ситуации можно вести себя по-разному, быть более гибкими, адаптивными и толерантными к новым и неопределённым ситуациям, опыту, людям или идеям. Высокая выраженность избегания неопределённости, свойственная как культуре, в которой живёт человек, так и в последствии ему самому, выступает в качестве предиктора, определяющего риск формирования личностной беспомощности.

Кроме показателей культурных ценностей, нами была изучена этническая идентичность респондентов из Центральной Азии. Так, предикативным маркером формирования личностной беспомощности выступил показатель позитивной этнической идентичности. Позитивная идентичность предполагает терпимое отношение к собственной этнической принадлежности, а также толерантные взгляды к другим этническим группам. Полученные данные относительно связи личностной беспомощности и позитивной этнической идентичности позволяют заключить, что сочетание позитивного отношения к собственному народу с позитивным отношением к другим народам в большей степени свойственно молодёжи из Центральной Азии с личностной беспомощностью. Показатели этнонигилизма, этноэгоизма, этноизоляционизма и этнофанатизма в большей степени выражены у испытуемых с самостоятельностью. Этнонигилизм подразумевает поиск субъектом социально-психологических вариантов для объединения с другими людьми, этнический признак при этом не выступает значимым показателем для выстраивания взаимоотношений. Людям с самостоятельностью проще выстроить гармоничные отношения с другими за счёт общих интересов, собственной уникальности, не прибегая к этническому критерию. 
Типы этнической идентичности, предполагающие в разной степени выраженность убеждения в превосходстве «своего» народа над другими, также в большей степени выражены у испытуемых с самостоятельностью и выступают в качестве фактора формирования самостоятельности. К данным типам идентичности относятся этноэгоизм, этноизоляционизм, этнофанатизм. Мигранты из стран Центральной Азии, выделяющие среди жителей «своих» и «чужих» по этническому критерию, признают приоритет этнических прав народа над правами человека, а также готовы оправдать наличие жертв в борьбе за благополучие своего народа. Выраженность этнической направленности задаёт более чёткое понимание собственных идеалов, позволяет осознать своё этническое превосходство, понять, кто является «своим», а кто «врагом». Все эти аспекты могут выступать в роли жизненного ориентира, позволяя субъекту быть более уверенным в себе и самостоятельным. Однако, выраженность перечисленных выше типов этнической идентичности может представлять угрозу в отношении национальной безопасности и провоцировать межэтнические конфликты. Данные результаты требуют дополнительной эмпирической проверки, но, тем не менее, открывают нам иное понимание феномена самостоятельности в контексте изучения этнический факторов формирования личностной беспомощности и самостоятельности.

В таблице 2 приведены значения дискриминантной функции.

Таблицуа 2.

Основные статистики канонической дискриминантной функции

\begin{tabular}{|c|c|c|c|c|c|c|c|}
\hline $\begin{array}{c}\text { Функ- } \\
\text { ция }\end{array}$ & $\begin{array}{c}\text { Собственное } \\
\text { значение }\end{array}$ & $\begin{array}{c}\text { \% дис- } \\
\text { персии }\end{array}$ & $\begin{array}{c}\text { Суммар- } \\
\text { ный \% }\end{array}$ & $\begin{array}{c}\text { Каноническая } \\
\text { корреляция }\end{array}$ & $\chi$ & $\begin{array}{c}\text { Хи- } \\
\text { квадрат }\end{array}$ & $\mathrm{p}$ \\
\hline 1 & 2,195 & 100,0 & 100,0 & 0,829 & 0,313 & 169,598 & 0,0001 \\
\hline
\end{tabular}

Опираясь на полученные данные, можем сказать, что каноническая дискриминантная функция информативна и объясняет $100 \%$ дисперсии, а также при значении $\chi$ Уилкса, равной 0,313 и статистической значимости $\mathrm{p}=0,0001$, указывает на то, что набор дискриминантных переменных обладает хорошей дискриминативной 
способностью. Тем не менее, в дискриминантное уравнение были включены не все переменные, что связано с учетом не только их дискриминативной способности, но и уникальным вкладом в совокупность с остальными переменными. В таблице 3 представлены коэффициенты канонической дискриминантной функции.

Таблицча 3.

Коэффициенты канонической дискриминантной функции

\begin{tabular}{|c|c|c|c|}
\hline Функция & Мужественность (MAS) & этноизоляционизм & этнофанатизм \\
\hline 1 & $-0,236$ & $-0,493$ & 0,354 \\
\hline
\end{tabular}

Коэффициенты канонической дискриминантной функции, указанные в таблице 3, характеризуют вклад каждой переменной в значение дискриминантной функции с учетом влияния остальных переменных. Так, наибольший вклад в значение дискриминантной функции, разделяющей мигрантов на самостоятельных и личностно беспомощных, вносят показатели мужественности (MAS), этноизоляционизма и этнофанатизма.

В таблице 4 отображены объединенные внутригрупповые корреляции между дискриминантными переменными и стандартизованной канонической дискриминантной функцией.

\section{Структурная матрица}

\begin{tabular}{|c|c|}
\hline & Функция \\
\hline Этноизоляционизм & $-0,145$ \\
\hline Мужественность (MAS) & $-0,139$ \\
\hline Этнофанатизм & $-0,076$ \\
\hline
\end{tabular}

Таблица 4.

Переменные, представленные в таблице 4, упорядочены по абсолютной величине корреляции в функции. Так, наибольшая абсолютная корреляция наблюдается между дискриминантной функцией и показателем этноизоляционизма. Согласно полученным данным, в дискриминантное уравнение вошли показатели этноизоляционизма, этнофанатизма и мужественности, которые вносят вклад в дифференциацию респондентов - мигрантов стран Центральной 
Азии - на личностно беспомощных и самостоятельных. Выраженность перечисленных показателей способствует формированию самостоятельности. При низком уровне выраженности данные показатели выступают факторами риска формирования личностной беспомощности.

\section{Заключение}

Изучение культурно-этнических факторов формирования личностной беспомощности включает в себя изучение этнических условий жизни индивида, системы культурных ценностей, а также - этнической идентичности субъекта. Данное исследование открывает возможность целостного и глубоко осмысления изучаемых феноменов - личностной беспомощности и самостоятельности, позволяет создать базу для разработки и апробации программ психопрофилактики и психологической коррекции личностной беспомощности, программ сопровождения процесса адаптации у мигрантов.

Исследование выполнено при поддержке гранта РФФИ (проект № 19-013-00949А Культурно-этнические детерминанты самостоятельности-личностной беспомощности молодежи России и стран ближнего зарубежья (на материале мигрантов из Центральной Азии)).

\section{Список литературы}

1. Антропология. Учебник для вузов. В.М. Харитонов, А.П. Ожигова, Е.3. Година: Владос, 2004. 272 с.

2. Климова М.О., Циринг Д.А. Диагностика личностной беспомощности у подростков: разработка и апробация психодиагностического инструментария. Сибирский психологический журнал. 2017. № 66. C. 130-140.

3. Миронов А.В. Этническая идентичность как фактор формирования самоотношения личности // Теория и практика общественного развития. 2012. № 11. С. 116-119. 
4. Пономарева И.В. Личностная беспомощность подростков из семей с нарушениями взаимоотношений. Челябинск: Печатный двор. 2013. $152 \mathrm{c}$.

5. Сизова Я.Н. Исследование способов преодоления трудностей и уровня волевой регуляции у подростков с личностной беспомощностью // Современные исследования социальных проблем. 2018. Т. 9, № 8. С. 175-188.

6. Сизова Я.Н., Евстафеева Е.А. Культурно-этнический фактор формирования личностной беспомощности: теоретические предпосылки исследования // Общество: социология, психология, педагогика. 2019. № 10. https://doi.org/10.24158/ spp.2019.10.12

7. Солдатова Г.У. Психология межэтнической напряженности. М., 1998. C. 40-63.

8. Стефаненко Т.Г. Этнопсихология. М.: Институт психологии РАН, «Академический проект», 1999. 320 с.

9. Циринг Д.А. Психология личностной беспомощности. М.: Академия. 2010. 410 с.

10. Циринг Д.А., Сизова Я.Н. Особенности взаимоотношений в семьях подростков с личностной беспомощностью различного типа // Высшее образование сегодня. 2018. № 1. С. 50-54.

11. Шварц Ш., Бутенко Т.П., Седова Д.С., Липатова А.С. Уточненная теория базовых индивидуальных ценностей. Применение в России // Психология. Журнал Высшей школы экономики. 2012. Т. 9, № 1. C. 43-70.

12. Hofstede G.H. Cultures and organizations: software of the mind. Mc Graw Hill. 2015. 279 p.

13. Safarova J. Characteristics of Ethnic Identity Among Students // Propósitos y Representaciones. 2020. Vol. 8 (2). http://dx.doi.org/10.20511/pyr2020. v8n2.464.

14. Vietze J., Juang L.P. Schachner M.K. Peer cultural socialisation: a resource for minority students' cultural identity, life satisfaction, and school values // Intercultural Education. 2019. Vol. 30-5. P. 579-598. https://doi. org/10.1080/14675986.2019.1586213. 
15. Warikoo N., Carter P. Cultural Explanations for Racial and Ethnic Stratification in Academic Achievement: A Call for a New and Improved Theory // Review of Educational Research. 2009. Vol. 79 (1). P. 366-394.

\section{References}

1. Haritonov V.M., Ozhigova A.P., Godina E.Z. Antropologiya. Uchebnik dlya vuzov [Anthropology. Textbook for universities]. M.: Vlados, 2004. $272 \mathrm{p}$.

2. Klimova M.O., Tsiring D.A. Diagnostika lichnostnoj bespomoshchnosti u podrostkov: razrabotka i aprobaciya psihodiagnosticheskogo instrumentariya [Diagnostics of personal helplessness in adolescents: development and testing of psychodiagnostic tools]. Sibirskij psihologicheskij zhurnal [Siberian Psychological Journal], 2017, no. 66, pp. 130-140.

3. Mironov A.V. Etnicheskaya identichnost' kak faktor formirovaniya samootnosheniya lichnosti [Ethnic identity as a factor in the formation of a person's self-attitude]. Teoriya i praktika obshchestvennogo razvitiya [Theory and practice of social development], 2012, no. 11, pp. 116-119.

4. Ponomareva I.V. Lichnostnaya bespomoshchnost'podrostkov iz semej s narusheniyami vzaimootnoshenij [Personal helplessness of adolescents from families with relationship disorders], Chelyabinsk: Pechatnyj dvor, 2013, 152 p.

5. Sizova Ya.N. Issledovanie sposobov preodoleniya trudnostej i urovnya volevoj regulyacii u podrostkov s lichnostnoj bespomoshchnost'yu [Research of ways to overcome difficulties and the level of volitional regulation in adolescents with personal helplessness]. Sovremennye issledovaniya social'nyh problem [Modern studies of social problems], 2018, vol. 9, no. 8, pp. 175-188.

6. Sizova Ya.N., Evstafeeva E.A. Kul'turno-etnicheskij faktor formirovaniya lichnostnoj bespomoshchnosti: teoreticheskie predposylki issledovaniya [Cultural and ethnic factor of personal helplessness formation: theoretical background of the study]. Obshchestvo: sociologiya, psihologiya, pedagogika [Society: sociology, psychology, pedagogy], 2019, no. 10. https://doi.org/10.24158/spp.2019.10.12. 
7. Soldatova G.U. Psihologiya mezhetnicheskoj napryazhennosti [Psychology of interethnic tension], M., 1998, pp. 40-63.

8. Stefanenko T.G. Etnopsihologiya [Ethnopsychology]. M.: Institut psihologii RAN, «Akademicheskij proekt», 1999, 320 p.

9. Tsiring D.A. Psihologiya lichnostnoj bespomoshchnosti [Psychology of personal helplessness]. M.: Akademiya, 2010, 410 p.

10. Tsiring D.A., Sizova Ya.N. Osobennosti vzaimootnoshenij v sem'yah podrostkov s lichnostnoj bespomoshchnost'yu razlichnogo tipa [Features of relationships in families of adolescents with personal helplessness of various types]. Vysshee obrazovanie segodnya [Higher education today], 2018, no. 1, pp. 50-54.

11. Shvarc Sh., Butenko T.P., Sedova D.S., Lipatova A.S. Utochnennaya teoriya bazovyh individual'nyh cennostej. primenenie v Rossii [Refined theory of basic individual values. application in Russia]. Psihologiya. Zhurnal Vysshej shkoly ekonomiki [Psychology. Journal of the Higher School of Economics], 2012, vol. 9, no. 1, pp. 43-70.

12. Hofstede G.H. Cultures and organizations: software of the mind. Mc Graw Hill, 2015, 279 p.

13. Safarova J. Characteristics of Ethnic Identity Among Students. Propósitos y Representaciones, 2020, vol. 8(2). http://dx.doi.org/10.20511/pyr2020. v8n2.464.

14. Vietze J., Juang L.P., Schachner M.K. Peer cultural socialisation: a resource for minority students' cultural identity, life satisfaction, and school values. Intercultural Education, 2019, 30-5, pp. 579-598. https://doi.or $\mathrm{g} / 10.1080 / 14675986.2019 .1586213$

15. Warikoo N., Carter P. Cultural Explanations for Racial and Ethnic Stratification in Academic Achievement: A Call for a New and Improved Theory. Review of Educational Research, 2009, vol. 79 (1), pp. 366-394.

\section{ДАННЫЕ ОБ АВТОРАХ}

Пономарева Ирина Владимировна, старший научный сотрудник, кандидат психологических наук, доцент Национальный исследовательский Томский государственный университет; Челябинский государственный университет 
пр. Ленина, 36, г. Томск, Томская область, 634050, Российская Федерация; ул. Братьев Кашириньхх, 129, г. Челябинск, Челябинская область, 454001, Российская Федераџия ivp-csu@ya.ru

Пахомова Яна Николаевна, научный сотрудник, кандидат психологических наук

Национальный исследовательский Томский государственный университет; Челябинский государственный университет пр. Ленина, 36, г. Томск, Томская область, 634050, Российская Федерация; ул. Братьев Кашириньхх, 129, г. Челябинск, Челябинская область, 454001, Российская Федераџия sizova159@ya.ru

Винькова Галина Александровна, профессор, доктор медицинских наук, профессор

Челябинский государственньй университет

ул. Братьев Кашириных, 129, г. Челябинск, Челябинская область, 454001, Российская Федерация vga2003@yandex.ru

\section{DATA ABOUT THE AUTHORS}

Irina V. Ponomareva, Senior Researcher, Laboratory of psychophysiology, Ph.D. in Psychology, Associate Professor

National Research Tomsk State University; Chelyabinsk State University

36, Lenin Ave., Tomsk, Tomsk Region, 634050, Russian Federation; 129, Bratiev Kashirinykh Str., Chelyabinsk, Chelyabinsk Region, 454001, Russian Federation

ivp-csu@ya.ru

SPIN-code: $8645-9023$

ORCID: 0000-0001-8600-3533

ResearcherID: E-8773-2017

Scopus Author ID: 57200443546 
Yana N. Pakhomova, Researcher, Laboratory of psychophysiology, Ph.D. in Psychology

National Research Tomsk State University; Chelyabinsk State University

36, Lenin Ave., Tomsk, Tomsk Region, 634050, Russian Federation; 129, Bratiev Kashirinykh Str., Chelyabinsk, Chelyabinsk Region, 454001, Russian Federation

sizova159@ya.ru

SPIN-code: 2960-1491

ORCID: 0000-0001-9000-7238

ResearcherID: B-4702-2018

Scopus Author ID: 57200443965

Galina A. Vinkova, Professor, Department of Psychology, Doctor of Medical Sciences, Professor

Chelyabinsk State University

129, Bratiev Kashirinykh Str., Chelyabinsk, Chelyabinsk Region, 454001, Russian Federation

vga2003@yandex.ru 